\title{
Chronic Total Occlusion of Left Main Coronary Artery- Surviving a Widow Maker
}

\author{
Rajshekhar.I.Koujalgi1 ${ }^{1, *}$, Prem Krishna Anandan ${ }^{2}$, Beeresha $^{3}$, B.Ramesh ${ }^{4}$, \\ Nagmani A C $C^{5}, C$ N Manjunath ${ }^{6}$
}

Sri Jayadeva Institute of Cardiovascular Science \& Research, India

Copyright (C) 2015 Horizon Research Publishing All rights reserved.

\begin{abstract}
Surviving a Left Main coronary artery (LMCA) total occlusion depends upon the presence of well-developed collaterals. We report a 44 year male patient, with past history of Ischemic heart disease, who underwent Angioplasty to Left Anterior Descending Artery (LAD) in 2009, and presented with Acute Coronary Syndrome (ACS)-Non ST Elevation of Myocardial Infarction (NSTEMI). Subsequently, cardiac catheterization revealed a total occlusion of the LMCA with dominant right coronary artery (RCA) giving collaterals to the left coronary arteries. The patient was immediately referred for coronary artery bypass surgery (CABG) and was symptom free on follow up. This case demonstrates the power of collateral circulation in protecting the patient from symptoms and death despite total occlusion of the LMCA.
\end{abstract}

Keywords Coronary Artery Disease, Left Main Coronary Artery Disease, Total Occlusions, Diagnostic Cardiac Catheterization, Widow Maker

\section{Introduction}

LMCA total occlusion, otherwise known as widow maker has a grave outcome if not recognised and intervened in time. It is an unusual manifestation of coronary atheromatous disease, with unknown prevalence and a frequency between $0.04 \%$ to $0.1 \%$. Presentation can be either recurrent angina or myocardial infarction (MI). Myocardial function and survival depends upon the presence of well-developed collaterals.

\section{Case Report}

A 44 year old male with past history of type II Diabetes Mellitus, Systemic Hypertension and anterior wall myocardial infarction, who underwent PTCA with stent to LAD five years back, presented with history of rest angina of 24 hours duration with elevated cardiac troponin $\mathrm{T}$ levels.
There was no history of dyspnea or syncope. His blood pressure on admission was $140 / 90 \mathrm{mmhg}$, heart rate of 80 beats per minute, Body mass index of $22 \mathrm{~kg} / \mathrm{m} 2$, and clinically normal cardiovascular and respiratory system on examination.

His electrocardiogram (ECG) on admission showed no fresh ST-T changes compared to the past ECG. His Hemoglobin was $14.3 \mathrm{gm} / \mathrm{dl}$, renal and liver function tests were normal, lipid profile showed hypertriglyceridemia. 2D echocardiogram showed akinetic left ventricular (LV) anterior, septal and apical segments, LV apical aneurysm, with LV ejection fraction of $35 \%$.

His coronary angiography(CAG)(FIG 1-2) showed left main coronary artery occluded at its origin along with the stented proximal LAD and Left circumflex coronary artery(LCX) being opacified retrogradely by heterocollaterals from a dominant RCA (Rentrops II).

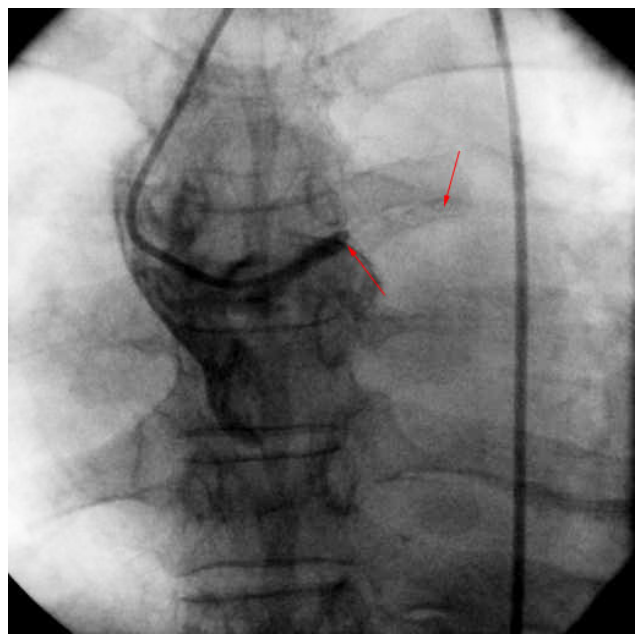

Figure 1. Left Coronary Angiogram-Showing Total LMCA Occlusion and LAD stent (arrows)

The patient was immediately referred for $\mathrm{CABG}$ and underwent a successful off pump coronary artery bypass grafting (OPCAB) with a left internal mammary artery (LIMA) graft to LAD and saphenous vein graft to diagonal branch of LAD and obtuse marginal branch (OM) of LCX. 
Post-operative stay was uneventful and he was discharged in a hemodynamically stable state. On first follow up after one month he was free of angina symptoms, but significant improvement in LV function was not yet appreciated.

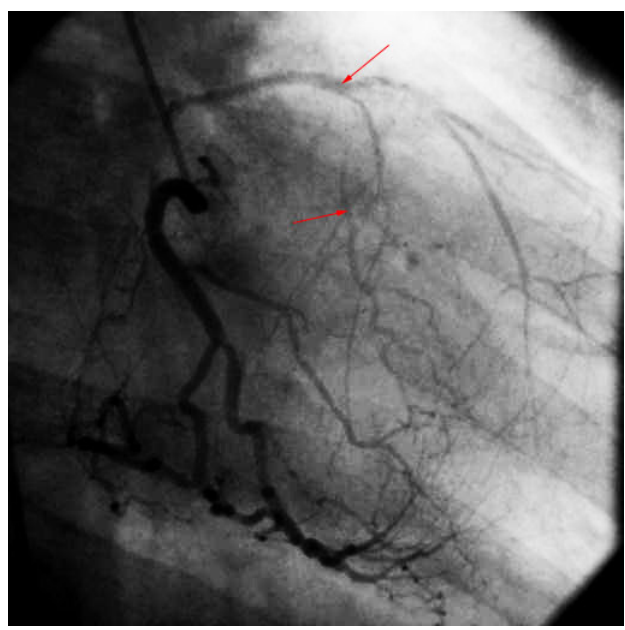

Figure 2. Right Coronary Angiogram Showing Normal RCA with Retrograde Filling of LAD\& LCX (arrows)

\section{Discussion}

Clinicians often refer to the LAD as the widow maker because obstruction here predisposes to a high incidence of sudden death ${ }^{1,2, .}$ On cardiac catheterization chronic total occlusion of LMCA had a frequency of $0.04 \%$ to $0.1 \%{ }^{3-5}$. Finding a chronic totally occluded LMCA is rare as most patients with acute or subacute occlusion of the LMCA have a high mortality and survival depends on the size and dominance of the RCA and the formation of collateral supply to the left coronary system., ${ }^{4,8}$ The degree of collateral circulation likely influences the symptoms experienced by patient. In a study it was suggested collateral circulation can prevent ischemia and preserve ventricular function, but collateral circulation does not appear to protect against exercise induced ischemia ${ }^{6,7}$ However in patients with LMCA occlusion and collaterals from RCA, undergoing CABG decreases symptoms and improves survival? Visualization of the distal left coronary arteries and decision regarding the possibility and placement of grafts are pivotal as the treatment of choice in left main disease is CABG. ${ }^{10}$ In a similar case series Joong et al reported two cases of chronic LMCA total occlusions and their long-term survival after successful surgical management. ${ }^{11}$

A rare finding chronic total occlusion of LMCA presenting with angina and only NSTEMI in our patient was possibly due to the extensive collaterals from RCA to LAD and LCX. The In-stent restenosis could be attributed to poor compliance to follow up, drugs and progression of coronary atherosclerosis.

\section{Conclusions}

The coronary collateral supply is important in freedom from symptoms and survival of a patient with total occlusion of left main coronary artery.

\section{REFERENCES}

[1] Topol, Eric J.; Califf, Robert M. (2007). Textbook of Cardiovascular Medicine. Lippincott Williams \& Wilkins. p. 283. ISBN 9780781770125. Retrieved 6 November 2014. The most worrisome type is the proximal left anterior descending (LAD) MI, often referred to as the widow-maker infarction, which carries a high mortality and is attributed to an occlusion of the LAD before or at the first septal perforator.

[2] Lewis, Kathryn (1 December 2009). Multiple Lead ECGs: A Practical Analysis of Arrhythmias. Cengage Learning. p. 10. ISBN 9781435441248. Retrieved 6 November 2014. The LAD is frequently implicated in sudden cardiac death, predominantly in adult males. Clinicians often refer to the $\mathrm{LAD}$ as the widow maker because obstruction here predisposes to a high incidence of sudden death

[3] Ward DE, Valantine H, Hui W. Occluded left main stem coronary artery. Report of five patients and review of published reports. Br Heart J. 1983;49(3):276-279.

[4] Greenspan M, Iskandrian AS, Segal BL, Kimbiris D, Bemis CE. Complete occlusion of the left main coronary artery. Am Heart J. 1979;98(1):83-86.

[5] Kanjwal MY, Carlson DE Jr, Schwartz JS. Chronic/subacute total occlusion of the left main coronary artery--a case report and review of literature. Angiology. 1999;50(11):937-945.

[6] Ha JW, Cho SY, Jang YS, Chung N, Shim WH, Kim SS. Collateral circulation in total occlusion of the left anterior descending or right coronary artery. Yonsei Med J. 1994;35(2):132-141

[7] Slunga L, Eriksson P, Osterman G. Complete occlusion of the left main coronary artery: clinical and angiographic observations in five cases. J Intern Med. 1989;225(2):123-127

[8] Sugishita K, Shimizu T, Kinugawa K, et al. Chronic total occlusion of the left main coronary artery. Intern Med. 1997;36(7):471-478.

[9] Valle M, Virtanen K, Hekali P, Frick MH. Survival with total occlusion of the left main coronary artery. Significance of the collateral circulation. Cathet Cardiovasc Diagn. 1979;5(3):269-275.

[10] Crosby IK, Wellons HA Jr, Bruwell L. Total occlusion of left main coronary artery. Incidence and management. J Thorac Cardiovasc Surg. 1979;77(3):389-391.

[11] Joong H. Choh, M.D et al. Survival with Total Occlusion of Left Main Coronary Artery.Tex Heart Inst J. 1984 Mar; 11(1): 64-68. 